\title{
Why are pyramidal cell firing rates increased with aging, and what can we do about it?
}

\author{
A Yadav*1,2,3, Christina M Weaver 1,2,3, Yuan Z Gao ${ }^{1,2,3}$, Jennifer I Luebke ${ }^{4}$ \\ and Susan L Wearne ${ }^{1,2,3}$
}

Address: ${ }^{1}$ Department of Neuroscience, Mount Sinai School of Medicine, New York, NY 10029, USA, ${ }^{2}$ Laboratory of Biomathematics, Mount Sinai School of Medicine, New York, NY 10029, USA, ${ }^{3}$ Computational Neurobiology and Imaging Center, Mount Sinai School of Medicine, New York, NY 10029, USA and ${ }^{4}$ Department of Anatomy and Neurobiology, Boston University, Boston, MA 02118, USA

Email: A Yadav* - aniruddha.yadav@mssm.edu

* Corresponding author

from Seventeenth Annual Computational Neuroscience Meeting: CNS*2008

Portland, OR, USA. 19-24 July 2008

Published: II July 2008

BMC Neuroscience 2008, 9(SuppI I):P5I doi:I0.II86/I47I-2202-9-SI-P5I

This abstract is available from: http://www.biomedcentral.com/I47I-2202/9/SI/P5 I

(c) 2008 Yadav et al; licensee BioMed Central Ltd.

Altered neuronal morphology and electrophysiological function in aged primates are correlated with cognitive deficits [1]. Recent experimental studies of young and aged layer $2 / 3$ pyramidal neurons of the prefrontal cortex (PFC) of rhesus monkeys show an age related increase in both the somatic input resistance and action potential (AP) firing rate [1]. Aged cells display fewer apical dendrites, and reduced spine numbers, although the average spine in an aged cell is larger [2]. Figure 1 compares the morphology and firing patterns for typical young (left column) and aged (right column) pyramidal cells from the PFC of rhesus monkeys [2], illustrating that an aged cell fires at a higher frequency for the same $2 \mathrm{~s}$ current injection (380 pA) at the soma, despite being similar in overall size and morphology to the young cell.

Through compartment modeling of these neurons, we extract aspects of altered morphology and electrophysiology that are central to age-related deterioration in cognitive function. We explore homeostatic mechanisms that can compensate for this deterioration partially or completely. To quantify homeostatic trade-offs between morphology and electrical function, we have designed morphologic metrics that include spine surface area, numbers of apical and basal dendrites, and volume of the soma, while active channel metrics are characterized by their maximal conductances, kinetics, and spatial distribution. By utilizing the concept of normalized sensitivity $[3,4]$, the effect of perturbations in these metrics on neu- ronal function characterized by AP firing rate, somatic input resistance, AP firing rate adaptation, electrotonic lengths, and transfer impedance, is determined in terms of unitless measures (sensitivities). By nature, unitless measures allow direct quantitative comparison between parameters as different as branch diameter $(\mu \mathrm{m})$ and channel densities $\left(\mathrm{mS} / \mathrm{cm}^{2}\right)$. Our preliminary investigations and experimental evidence of an age related increase in slow Afterhyperpolarization (sAHP) and hyperpolarization activated cation $(\mathrm{H})$ channel densities, suggest sev-

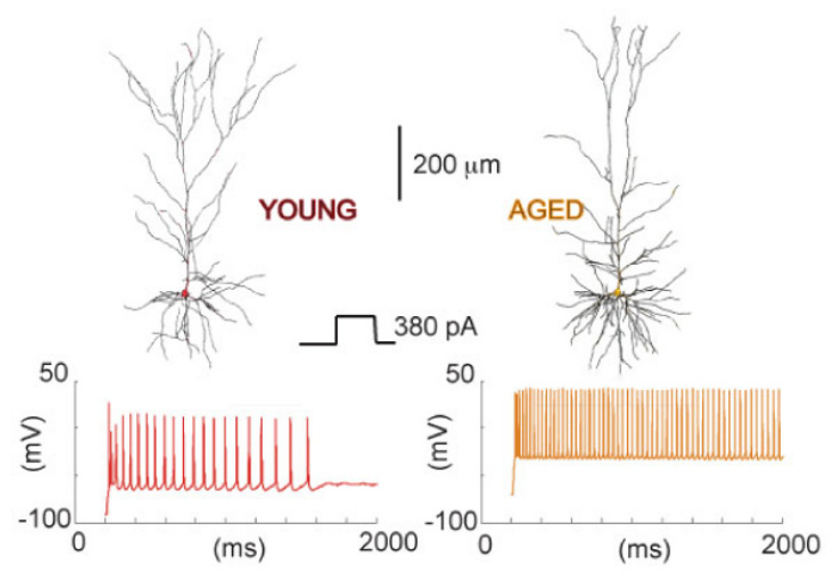

Figure I

LAYER 2/3 NEURONS. 
eral alternative hypotheses regarding altered neuron function with age. The increased sAHP, for example, could reflect a compensatory mechanism acting to minimize the firing rate increases that accompany morphologic change, or it may be an epiphenomemon of altered calcium influx observed in normal aging. Our analytical techniques allow us to predict the functional consequences of these alternatives. We also predict biologically realistic mechanisms, involving combinations of morphologic and active membrane properties, that either subserve altered neuron function, or are compensatory in nature. Using these techniques, we identify compensatory mechanisms that can restore cellular function of aged neurons to normal levels, despite the significant morphologic changes that characterize normal aging.

\section{References}

I. Chang Yu-Ming, Rosene Douglas L, Killany Ronald J, Mangiamele Lisa A, Luebke Jennifer I: Increased action potential firing rates of Layer $2 / 3$ pyramidal cells in the prefrontal cortex are significantly related to cognitive performance in aged monkeys. Cerebral Cortex 2005, I 5(4):409-4I8.

2. Kabaso D, Weaver CM, Rocher AB, Luebke II, Wearne SL: Contributions of the age-related changes in dendrites and spine geometry to increased excitability in neurons of the prefrontal cortex of monkeys, Program No. 477.4. Neuroscience 2007.

3. Satelli A, Chan K, Scott EM, editors: Sensitivity analysis. New York, John Wiley \& Sons; 2000.

4. Weaver Christina M, Wearne Susan L: Neuronal firing sensitivity to morphologic and active membrane parameters. PLOS Comput Biol 2008, 4:1-19.
Publish with Bio Med Central and every scientist can read your work free of charge

"BioMed Central will be the most significant development for disseminating the results of biomedical research in our lifetime. "

Sir Paul Nurse, Cancer Research UK

Your research papers will be:

- available free of charge to the entire biomedical community

- peer reviewed and published immediately upon acceptance

- cited in PubMed and archived on PubMed Central

- yours - you keep the copyright

Submit your manuscript here:

http://www.biomedcentral.com/info/publishing_adv.asp 